\title{
Oceans of Discourses: Utilizing Q Methodology for Analyzing Perceptions on Marine Biodiversity Conservation in the Kogelberg Biosphere Reserve, South Africa
}

\author{
Kristin Hagan ${ }^{1 *}$ and Samantha Williams ${ }^{2,3}$ \\ ${ }^{1}$ Department of Human Geography, Planning and International Development, University of Amsterdam, Amsterdam, \\ Netherlands, ${ }^{2}$ Department of Environmental and Geographical Sciences, University of Cape Town, Cape Town, South Africa, \\ ${ }^{3}$ Department of Geography and Environmental Studies, Stellenbosch University, Stellenbosch, South Africa
}

OPEN ACCESS

Edited by:

Annette Breckwoldt, Leibniz Center for Tropical Marine

Ecology, Germany

Reviewed by:

Fabio Badalamenti, National Research Council, Italy

Elizabeth Ingrid Van Putten, CSIRO, Australia

Mary Mackay

University of Tasmania, Australia

*Correspondence:

Kristin Hagan

hagan.kristin@gmail.com

Specialty section:

This article was submitted to

Marine Conservation and

Sustainability,

a section of the journal

Frontiers in Marine Science

Received: 03 June 2016 Accepted: 15 September 2016

Published: 29 September 2016

Citation:

Hagan K and Williams S (2016) Oceans of Discourses: Utilizing $Q$

Methodology for Analyzing

Perceptions on Marine Biodiversity

Conservation in the Kogelberg

Biosphere Reserve, South Africa.

Front. Mar. Sci. 3:188.

doi: 10.3389/fmars.2016.00188
This paper attempts to empirically investigate perceptions regarding marine biodiversity conservation among different stakeholders of the Kogelberg Biosphere Reserve, South Africa. The study's data was collected by following $Q$ methodology in combination with semi-structured interviews and participant observation. $Q$ methodology combines elements from quantitative and qualitative research traditions, providing researchers with a systematic and rigorous means to study human subjectivities. Primary data were gathered from stakeholders who either live, work, or have performed research in the Kogelberg Biosphere Reserve. A combination of interpretative discourse analysis and $Q$ factor analysis was employed to identify perceptions. The results reveal that there are two operating discourses with clear stakeholder divisions. The science discourse is characterized by its scientific management-based ecological approach. On the other hand, the livelihoods discourse is primarily concerned about the social implications brought about by Kogelberg as a biosphere reserve. The paper goes on to argue that the meaning people attach to the concept of "marine biodiversity conservation" is relational as it is based on their lived experience. It further highlights the importance of performing context-specific social research of protected areas, as it is difficult for conservation projects to meet both ecological and social needs without understanding the viewpoints of engaged stakeholders and local communities.

Keywords: marine biodiversity conservation, Kogelberg biosphere reserve, environmental discourses, environmental subjectivities, $Q$ methodology, perceptions, nature conservation

\section{INTRODUCTION}

Loss of biodiversity is one of the most prominent aspects of the environmental crisis the world is facing. It is estimated that the earth is home to somewhere between 5 and 15 million species, of which only 1.8 million are known to science. While species dying out is a natural process, the current extinction rates are assumed to be 100 to 1000 times greater than the "normal" rate, which 
is largely due to human activities such as habitat destruction and fragmentation, overharvesting or pollution (Stoll-Kleemann and Bertzky, 2004: p. 1; Kearns, 2010: p. 7). Loss of biodiversity and rapid depletion of natural resources is present in all known ecosystems. While the ocean has been regarded as a source of infinite resources for a long time, it is estimated that $70 \%$ of the earth's commercially targeted fish species have been overfished to the point where their stocks are in grave danger of being depleted. On a global scale, some of the most threatened marine species include whales, dolphins, salmon, sea turtles, sharks, manatees and dugongs ${ }^{1}$.

Biodiversity loss is therefore expressed as one of the main contemporary environmental concerns along with climate change and desertification (United Nations, 2002: p. 3). In response to reduce the loss of biodiversity worldwide, UNESCO has created 651 biosphere reserves (BR) in 120 countries worldwide as part of the Man and the Biosphere program (MAB). Biosphere reserves are experimental places, which see interdisciplinary approaches being tested to understand and manage changes and interactions between social and ecological systems, including conflict prevention and management of biodiversity. These reserves can be more closely described as areas comprising terrestrial, marine and coastal ecosystems, promoting biodiversity conservation of species as well as sustainable development of local human populations ${ }^{2}$. Such a reserve is an open area without any fences to "keep people out" and "nature in." Furthermore, BRs are governed in such a way that local communities, farmers, conservation agencies and local governments are committed to protect the landscape and its biodiversity together ${ }^{3}$. Participation of local communities in the management of biospheres is seen as crucial to make the project succeed, while at the same time aiming to include traditional ecological knowledge into ecosystem management. However, many attempts of conserving biodiversity have failed, and the BR concept as put forward by UNESCO is no exception (Stoll-Kleemann and Bertzky, 2004; Hyman, 2006). Many of the BRs neither have the resources nor the capacity to meet the global mandate put forward by UNESCO, a problem that is particularly evident in developing countries. Another important problem in a biosocio-economic system is that these systems are dynamic and complex, and consist of many interactions between humans and institutions. As a consequence, conflicts emerge on multiple levels. Stoll-Kleemann and Bertzky (2004: p. 2) note that biodiversity conflicts are often a result of the different preferences, values and objectives of different actors.

Environmental arguments, such as protection and conservation of biodiversity might appear to be factual and scientific, but they are also meaningful, ethical and suggestive (Næss, 1974: p. xxiii), representing a certain discursive perception of an issue. However, the ways in which individuals think about and understand environmental problems such as biodiversity

\footnotetext{
${ }^{1}$ Marinebio website, http://marinebio.org/oceans/threatened-endangeredspecies/ Accessed 10.08.2015.

${ }^{2}$ UNESCO website, http://www.unesco.org/new/en/natural-sciences/ environment/ecological-sciences/biosphere-reserves/ Accessed 07.08.2015.

${ }^{3}$ Kogelberg Biosphere Reserve website, http://www.kogelbergbiospherereserve.co. $\mathrm{za}$ Accessed 10.08.2015.
}

conservation, is a vital issue in the study of environmental politics that often remains unexplored in the literature. Yet, this issue should be regarded as one of central importance because "until we know the 'discourses' people use about the environment, it will be very hard to judge what, and whether, environmental policies will be socially acceptable, and therefore capable of being implemented" (Barry and Proops, 1999: p. 338). Reality is socially constructed; therefore the analysis of meaning becomes central. In this way, it is not an environmental phenomenon in itself that is important, but the way in which society makes sense of this phenomenon. The meaning attributed to a concept such as "biodiversity conservation" affects the outcomes, institutions and laws, and further becomes the context, or discourse, in which environmental issues are talked about.

These meanings do not appear out of nothing, but are the result of a particular set of operational routines and accepted norms and rules that give coherence to social life (Hajer and Versteeg, 2005: pp. 176-177). Understanding the local context and the local way of thinking about environmental issues is therefore crucial for creating development projects and plans that aim at protecting biodiversity. Furthermore, the study of environmental perceptions in particular is very important in creating an understanding of the social complexities embedded in the environmental crisis.

This research has set out to contribute to the debate of biodiversity conservation and how differing discourses influence stakeholder perceptions and management of BRs. In order to investigate perceptions of marine biodiversity conservation, the study utilized a case study approach to understand how different stakeholders of a BR perceive biodiversity conservation of marine areas. The area of focus was the Kogelberg Biosphere Reserve located in South Africa. The study furthermore aimed to illustrate the utility of $\mathrm{Q}$ methodology for conducting perception-based research. The following sections will provide the background and context to the case study under investigation, before then turning to the actual process of applying Q methodology.

\section{CONSERVATION THROUGH THE ESTABLISHMENT OF BIOSPHERE RESERVES}

The Kogelberg Biosphere Reserve (KBR; Figure 1) was proclaimed as South Africa's first BR in 1998 (Turpie et al., 2009: p. 1). Some of the objectives highlighted in the establishment of BRs include the preservation and sustainable utilization of natural resources, as well as economic development that aims to be socially and environmentally just. It also includes education, monitoring and research as core and ongoing priorities (Tucker, 2013: p. 2). These areas are typically divided into core areas (where the highest level of protection is afforded and little or no consumptive uses occur), buffer zones (surround the core, and limited development and activities occur) and transitional zones where a range of activities and developments (i.e., including farming, residential or resort projects) take place ${ }^{4}$. Furthermore,

${ }^{4}$ Kogelberg Biosphere Reserve Company website, http://www.kbrc.org.za/ Accessed 05.04.2016. 


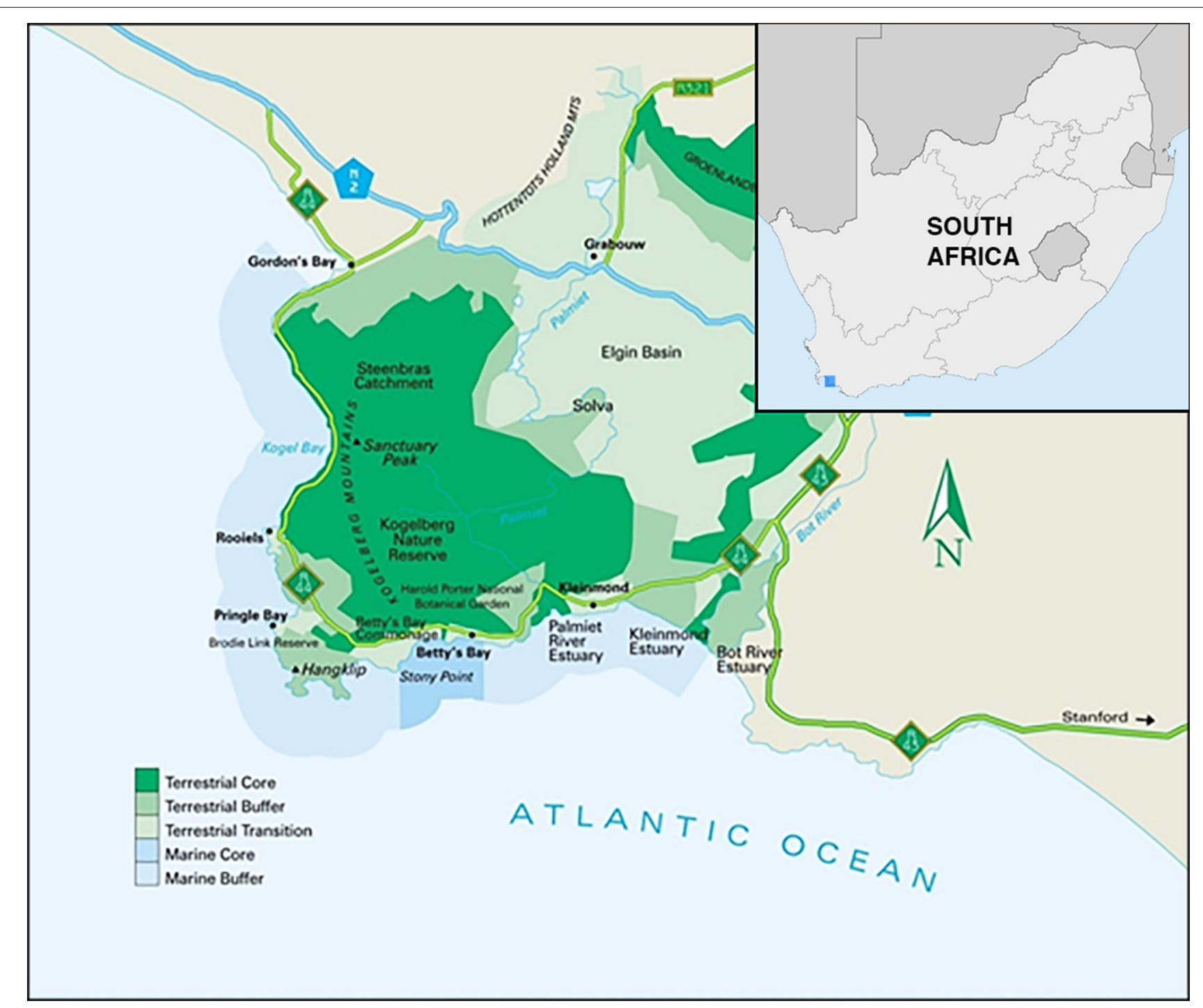

FIGURE 1 | Map of location, towns and zones of Kogelberg Biosphere Reserve, South Africa ${ }^{5}$.

BRs are managed by a range of organizations, including government departments, national parks authorities, provincial conservation bodies, local government departments, regional and municipal councils, non-governmental organizations (NGOs), community organizations, also with participation of researchers and universities.

The KBR is located in an area known as the Cape Floral Kingdom, comprising approximately 100,000 hectares at land and at sea ${ }^{6}$. This area has approximately 5800 endemic plant species, which is more for its area than anywhere else in the world". The KBR, also known as the "heart of the floral kingdom,"

\footnotetext{
${ }^{5}$ Map courtesy of Johns and Johns (2001). Edited by Stephen Young.

${ }^{6} \mathrm{KBRC}$ Kogelberg Biosphere Reserve Company website, http://www.kbrc.org.za/ index.php?dirname=docs_09about/history Accessed 20.06.2016.

${ }^{7}$ Kogelberg Biosphere Reserve Company website, http://www.kbrc.org.za/index. php?dirname=docs_03nature/flora Accessed 24.08.2016.
}

contains rich wildlife with a variety of different bird, amphibian and mammal species, and boasts with South Africa's largest penguin colony. About $30 \%$ of the KBR consists of marine areas, which are particularly biodiversity rich. This is where the cold Atlantic currents meet the Indian Ocean's warm waters, creating a home for a variety of marine species. The reserve starts in the Atlantic Ocean, $7.5 \mathrm{~km}$ from land, and stretches two nautical miles out to sea ${ }^{8}$. Being located in the Overberg municipality, the area is surrounded by small villages that include Rooi- Els, Pringle Bay, Betty's Bay and Kleinmond (Turpie et al., 2009: p. 3). In terms of development and economic activity, the trade and services sectors make up almost half of the economic production, with tourism playing a vital role (Turpie et al., 2009: p. 9). Being in close proximity to the coast has meant that the inhabitants

${ }^{8}$ Kogelberg Biosphere Reserve Company website, http://www.kbrc.org.za/ Accessed 05.04.2016. 
of the surrounding villages have developed a dependency and relationship with the sea. Primary use of the coast and its resources include the harvesting of abalone (Haliotis midae), west coast rock lobster (Jasus lalandii), line fish and kelp. In the recent past, the harvesting of abalone has seen a moratorium being placed on the resource by the National department of forestry and fisheries as incidences of poaching and overharvesting are driving the species toward extinction. The tradition and history of fishing in one particular village, Kleinmond, has been well established and dates back many generations. However, the continued illegal harvesting and pressures for greater access to the coastal marine resources by local resource users (amongst others) of the KBR and elsewhere along the country's coast have been a subject of concern for the National department of forestry and fisheries (Turpie et al., 2009: pp. iv-vi; Sunde, 2014: p. 23). As a result strict controls have been implemented by resource managers, and various efforts directed to streamline conservation efforts and economic and livelihood considerations within the KBR.

Management responsibility for the KBR is shared by a group of local and regional stakeholders. Its key management body is the Kogelberg Biosphere Reserve Company (KBRC), which works in collaboration with stakeholders from government, academia, business and $\mathrm{NGOs}^{9}$. In this management structure there are different subgroups or stakeholder working groups. The Kogelberg Marine Working Group (KMWG) is one such gathering of involved stakeholders. It was established in 2009, with the aim to contribute to the management of a no-take Marine Protected Area (MPA) in Betty's Bay (see Figure 1), which was established to facilitate the recovery of fish stocks and prevent marine species from being overharvested. The KMWG deals with marine and coastal environmental and social challenges (such as curbing poaching to protect the interest of the fishers) (Anchor Environmental, 2009: p. 4; (Hagan, 2016): pp. 15-18). The rationale for establishing a BR in the Kogelberg area was to ensure better biodiversity conservation through stakeholder involvement. It was envisaged that it would also address issues related to development pressures and poverty alleviation (Hyman, 2006: p. 23). However, the KBR has not achieved all of its desired successes, which has resulted in limited conservation and social developmental outcomes and stakeholders who struggle to cooperate (Hyman, 2006: p. 1; (Müller, 2010): p. 152; (Hagan, 2016): p. 56). While previous studies have pointed out that stakeholders in the KBR are facing management and cooperation difficulties as a result of divergent interests and perceptions (Hyman, 2006: p. 84-88; Müller, 2010: p. 152), this study has focused on stakeholders' perceptions of marine biodiversity conservation in more detail. The original study ${ }^{10}$ looked at five key stakeholder groups of the KMWG: CapeNature, scientists, small-scale fishers, World Wide Fund for Nature (WWF) and Seawatch (Hagan, 2016: pp. 18-19). This article will not discuss the latter two, as only two individuals from each of these Non-Governmental Organizations (NGOs) were working directly on marine conservation in

\footnotetext{
${ }^{9}$ Kogelberg Biosphere Reserve Company website, http://www.kbrc.org.za/index. php?dirname=docs_04projects/partners Accessed 12.05.2016.

${ }^{10}$ This paper draws on research undertaken as part of the first author's master's dissertation.
}

the KBR. CapeNature is a governmental institution that chairs the KMWG. They have the statutory responsibility for biodiversity conservation in the Western Cape as governed by the Western Cape Nature Conservation Board Act 15 of $1998^{11}$. Other stakeholders include both natural and social scientists, providing inputs in terms of management recommendations, monitoring and evaluation, as well as participation in stakeholder engagement. The fishers' group refers to men and women from the fishing villages of the KBR, whose livelihoods depend on small-scale fishing.

\section{MATERIALS AND METHODS}

In order to gain an understanding of the different ways marine biodiversity conservation in the KBR is perceived, data gathering was carried out using Q methodology in combination with semi-structured interviews and participant observation. The data from this process was analyzed using $\mathrm{Q}$ factor analysis and interpretative discourse analysis. A "discourse" is in this context understood as " $a$ shared way of apprehending the world. Embedded in language, it enables those who subscribe to it to interpret bits of information and put them together into coherent stories or accounts. Discourses construct meanings and relationships, helping define common sense and legitimate knowledge. Each discourse rests on assumptions, judgments, and contentions that provide the basic terms for analysis, debates, agreements, and disagreements (Dryzek, 2013: pp. 9-10).

\section{Q Methodology}

In the 1930s, the psychologist Stephenson (1953) developed Q methodology as a means to systematically study human subjectivity. The methodology combines the strengths of both quantitative and qualitative research traditions, and is suitable to investigate questions about personal experience and matters regarding taste, values and beliefs (Baker, 2006: p. 2343). Q method is primarily used in psychology, but it has also been embraced by scientists as a means to investigate human subjectivity on a variety of issues, particularly in politics and health research (Eden et al., 2005: p. 414). In later years, Q method has also rapidly expanded to environmental studies (Dasgupta and Vira, 2005: p. 2; Eden et al., 2005: p. 414; Webler et al., 2009: p. 8). Previous publications in social environmental research have scrutinized a wide range of topics, including environmental policy (Addams and Proops, 2000), global environmental change (Niemeyer et al., 2005), environmental management (Bischof, 2010), successful biodiversity conservation (West et al., 2016), and animal rights (Kalof, 2000). The method has also been utilized in work on environmental policy and environmental discourses in order to gain a more thorough understanding of stakeholder perceptions (Dasgupta and Vira, 2005; Guimaraães, 2010; Pike et al., 2014).

All Q studies are reconstructive and characterized by two key features. Firstly, the collection of data is done in form of Q sorts (Watts and Stenner, 2012: p. 178). This is typically

\footnotetext{
${ }^{11}$ CapeNature website, http://www.capenature.co.za/about-us/ Accessed 12.05.2016.
} 
(but not always) done by presenting people with a sample of statements about a topic, which is referred to as the Q-set. The selected respondents, called the P-set, are instructed to rank-order the statements from their personal point of view on a score sheet. Following this process, which is called the $\mathrm{Q}$ sort, people give their subjective meaning to the statements and thus reveal their subjective viewpoint (Van Exel and de Graaf, 2005: p. 1). Secondly, these Q sorts are factor-analyzed for establishing different patterns (Watts and Stenner, 2012: p. 178). Unlike standard survey analysis, Q methodology is not aimed at establishing patterns across individual characteristics such as age, gender and class. Instead it looks at patterns within and across individuals by focusing on their discursive understanding of a particular issue. It works on the assumption that there are a limited number of ordered patternings within a particular discursive realm, attempting to reveal those patterns in a structured and interpretable way (Barry and Proops, 1999: p. 339). The method is primarily explorative, for qualitative recognition of the mere existence of subjective views instead of measurement of pre-defined attitudes or perceptions. One of the main strengths of the method is that it provides statistically significant results from a reasonably low sample size (Brown, 1993: p. 94). Furthermore, it converts in-depth subjective information into quantifiable data in a way that traditional methods are not capable of Pike et al. (2014: p. 667).

\section{Administering the $\mathbf{Q}$ Sort}

Influenced by the steps created by Brown (1993) and later elaborated by Van Exel and de Graaf (2005), this Q study was conducted by following six steps; (1) defining the concourse; (2) developing the Q sample; (3) selecting the P-set; (4) Q sorting; (5) semi-structured interviews; and (6) analysis and interpretation.

Employing Q methodology, the first and most important step is to identify all the possible statements the actors within the relevant domain could make about the subject matter (Van Exel and de Graaf, 2005 : p. 4), in this case marine biodiversity conservation. The concourse, or "the flow of communicability surrounding any topic" (Brown, 1993: p. 94) was collected through key informant interviews with two representatives from each stakeholder group, as well as interviews and informal conversations with other members of the identified stakeholders, living or working in the KBR. A snowball sampling method was employed after attending a KMWG meeting in order to meet and contact relevant respondents. A purposive sampling approach was also employed with people who had relevant views on the matter without being directly related to the KBR context. These included fishers from other parts of the coast (outside the KBR) as well as conservation biologists and politicians working with nature reserves in the Western Cape. This was done to triangulate the various ideas surrounding biodiversity conservation in general and of marine areas in particular. These interviews and conversations (about 40 in total) resulted in hundreds of statements, which were transcribed, coded and divided into categories. These categories emerged inductively from the coding process, focusing on the most re-occurring issues. For instance, issues related to the MPA came up frequently and were therefore included, while gender was only brought up once and thus excluded. The Q sample was selected by choosing a few statements from each category (Webler et al., 2009: p. 10). Particular emphasis was placed on interviews with people living and working in the $\mathrm{KBR}$, minutes from meetings of the KMWG and scientific literature from the area. This resulted in 45 statements being collated. In this way, the selection procedure was based on field observation and interview data, in contrast to being based on pre-existing theory and categorizations. In addition to the Q sorting task, a key focus of the study was to emphasize the qualitative interview in combination with each $\mathrm{Q}$ sort. The Q sorts and interviews were set up to be no longer than $1 \mathrm{~h}$, therefore the amount of statements had to be reduced accordingly. The selection procedure used experts (social scientists who had worked in the KBR during the last 2 years but were no longer actively involved) as a means of piloting the suitability of the Q sample. This resulted in a final Q set consisting of 23 statements (see Table 1 below).

The next step was to develop the P-set, which is a "structured sample of respondents who are theoretically relevant to the problem under consideration. (...) The aim is to have four or five persons defining each anticipated viewpoint, which are often two to four, and rarely more than six" (Van Exel and de Graaf, 2005: p. 6). From the three stakeholder groups, eleven key informants were selected; four scientists (two social, two natural scientists), four fishers and the three CapeNature managers responsible for the KBR. As there is a limited amount of dedicated people who are engaged in the KMWG or the daily operations of the coastal areas of the KBR, the authors prioritized key informants with high levels of influence and engagement. The original study, which also involved Seawatch and WWF, contained 15 respondents for Q sorting. One of the benefits of Q methodology is that only few participants are needed to give statistical significant results. According to Barry and Proops (1999), as few as 12 participants can generate statistically meaningful results, because each participant's Q sort provides a vast amount of information (Barry and Proops, 1999: p. 334).

The Q set was given to the respondent in form of a deck of randomly numbered cards. Each card contained one statement from the final Q sample. The respondent was first instructed to sort the deck into three piles; "agree," "neutral/undecided," and "disagree," depending on his/her personal point of view. Thereafter, the respondent was instructed to sort out the statements on a score sheet with a pyramidal, or "quasi-normal," sorting distribution, ranging from "strongly disagree" $(-4)$ to "strongly agree" (4). The sorting distribution was pre-arranged; the whole $\mathrm{Q}$ set had to be allocated a ranking relative to one another within this distribution (see Figure 2). Each Q sorting was combined with an interview. During the sorting procedure, the respondent could choose whether to talk the researcher through each statement, or to sort first and do a follow-up interview afterwards. After each sorting, the respondent was asked to elaborate on his/her point of view, explain the most salient statements, and discuss whether there was any themes the respondent felt missing in the deck.

The Q sorts were subject to Q factor analysis, which is the most quantitative part of $\mathrm{Q}$. The factor analysis was carried out 
TABLE 1 | Statements, with scores on the two extracted discourses, sorted from consensus to strongest deviation.

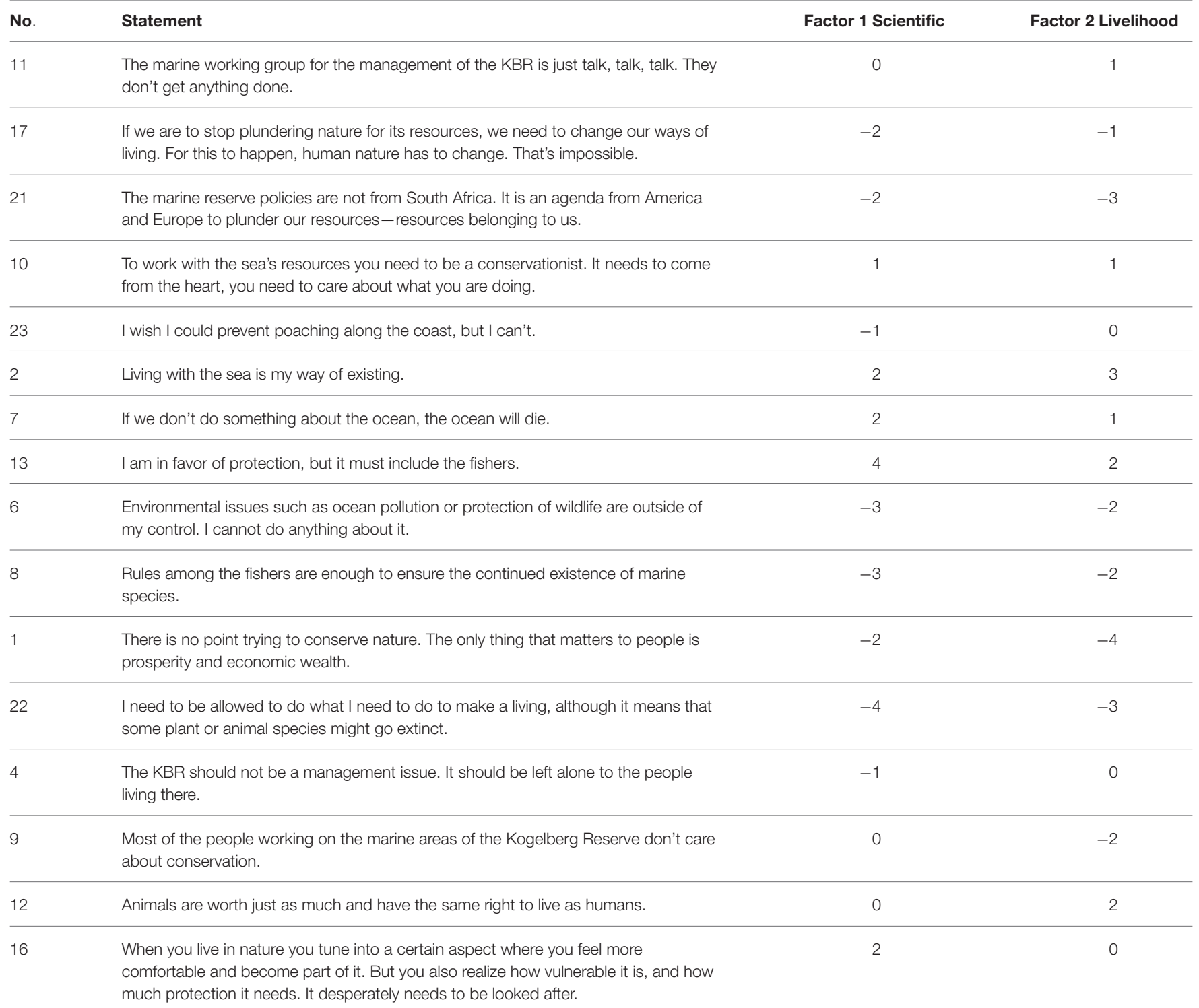

$3 \quad$ We need to have non-catch areas where no one is allowed to fish, and open areas where only local fishers are allowed to fish. The commercial industry must be left out of the equation.

\begin{tabular}{|c|c|c|c|}
\hline 14 & Our government officials are corrupt. & 1 & -1 \\
\hline 15 & The conservation ideal is that nature is left as close to its natural state as possible. & 1 & 0 \\
\hline 5 & If the abalone goes extinct, the ecosystem becomes unbalanced. & 3 & 0 \\
\hline 20 & $\begin{array}{l}\text { The way that humans exist and live today, their techniques for production and } \\
\text { acquisition of resources, are no longer at pace with the natural state. We have } \\
\text { outstripped the ability for natural ecosystems to recover from, and provide for, our } \\
\text { requirements. }\end{array}$ & 3 & -1 \\
\hline 18 & $\begin{array}{l}\text { The fishers are the protectors of the fishing areas and the sea, but by imposing MPAs } \\
\text { without our permission, the responsibility is taken away from us. }\end{array}$ & 0 & 4 \\
\hline 19 & $\begin{array}{l}\text { If there is a problem of decreasing fish stocks one must start with introducing } \\
\text { restrictions on the big fish boats, not on the small scale fishers who fish for their } \\
\text { livelihood. }\end{array}$ & -1 & 3 \\
\hline
\end{tabular}




\section{$\begin{array}{ll}\text { Disagree } & \text { Agree }\end{array}$}

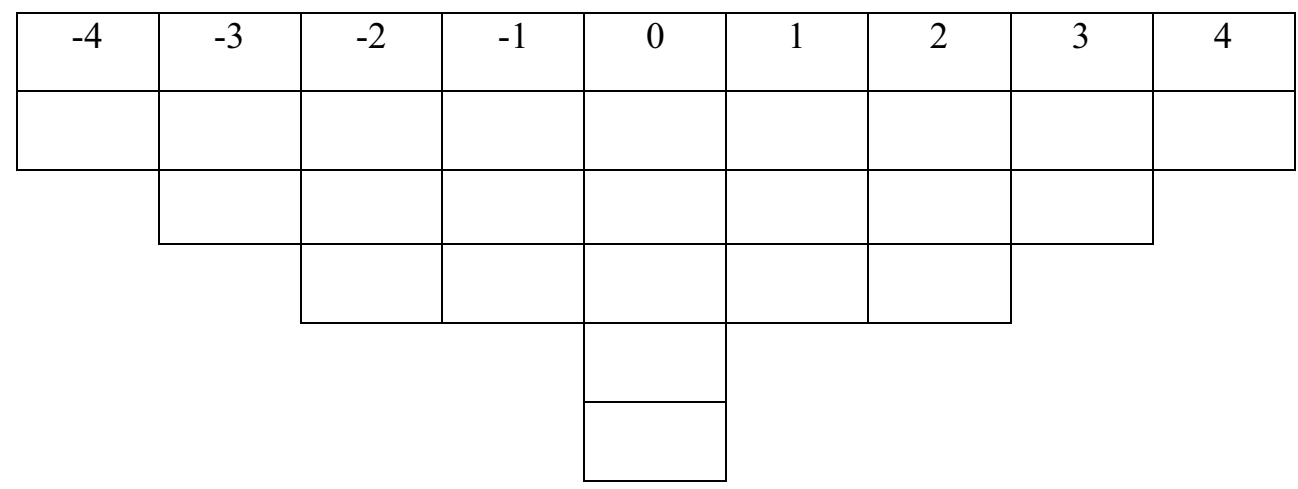

FIGURE 2 | Pre-arranged frequency distribution.

with the help of PQMETHOD-2.35 $5^{12}$, particularly designed for $\mathrm{Q}$ methodology. The package correlates every respondent's Q sort with every other Q sort. The resulting correlation matrix was then used for a centroid factor analysis (to define centers of gravity in the matrix and express these in specific terms; (Brown, 1993): p. 113). Varimax rotation was then used to rotate the remaining factors into a "simple structure" in order to extract factors that are significant according to the protocols of Q (Barry and Proops, 1999: p. 341). The package extracts all significant factors and conveys them as the "best estimate" of the sorts that represent them (Barry and Proops, 1999), capturing the common essence of the sorts. Based on their correlation to certain factors, the package provides a way of recognizing fundamentally different viewpoints and grouping respondents around these. The factors resulting from this analysis are not necessarily represented by any specific individual, but rather represent an "ideal type," which is a virtual respondent that is fully representing one of the distinguished viewpoints (Bischof, 2010: p. 605). Usually, each respondent has aspects of more than one "ideal" sort in their personal sort. Q sorts that come closest to this ideal are listed. The significance of a factor is determined statistically by its Eigenvalue (i.e., the sum of squares of the factor loadings). Eigenvalues higher than 1 are considered significant (Van Exel and de Graaf, 2005: p. 18). Another statistical criterion is the composite reliability ${ }^{13}$ of a factor, which depends on how many respondents define it. The more respondents define a factor, the higher the reliability (Dasgupta and Vira, 2005: p. 14). A factor should be defined by at least five respondents. This will result in a factor reliability of $95 \%$, which is sufficient to obtain a clear factor reading (du Plessis, 2005: p. 168). Correlation between an individual Q sort

\footnotetext{
${ }^{12}$ Schmolck, P. (2015) The PQ Method Page, online: http://schmolck.userweb. mwn.de/qmethod/ Accessed 01.02.2016.

${ }^{13}$ In PQMethod the formula $\mathrm{Rxx}=0,80 \mathrm{p} /[1+(\mathrm{p}-1), 080]$ is built into the program. 0,80 is the presumed average reliability of the $\mathrm{Q}$ sorts comprising the factor, while $\mathrm{p}$ is the number of those $\mathrm{Q}$ sorts. $\mathrm{Rxx}$ is the test-retest reliability coefficient. When $\mathrm{p}=5 \mathrm{Q}$ sorts the factor reliability is $\mathrm{Rxx}=0,80(5) /[1+(5$ $-1), 80]=0,9524$ (from du Plessis, 2005:169).
}

and shared factor was considered significant if a factor loading exceeded \pm 0.36 (West et al., 2016: p. 186).

The "ideal" Q sorts resulting from this procedure were interpreted along with the interview data to gain a better understanding of the outcomes of the factor analysis. As most respondents expressed their view on each single statement in the $\mathrm{Q}$ deck and answered interview questions related to these themes, the interview data carried extensive amounts of information that could be directly attached to each quote. This data assisted in interpreting the meaning of each statement and understanding the rationale behind why statements were sorted in a particular order (Gallagher and Porock, 2010: p. 298). In addition to the factor analysis, interview data and observations from the field were subject to interpretative discourse analysis to triangulate the results. Interpretative discourse analysis is committed to gaining an in-depth understanding of the actors' frame of reference, and possesses a view of language as being constructive rather than merely representational. It emphasizes the social construction of meaning and the central role of language as a symbolic medium in constructing social reality (Heracleous, 2006: pp. 11-12). Prior to the $\mathrm{Q}$ factor analysis, all the interviews and accompanied field observations were coded and analyzed separately, focusing on elements such as language, content, meaning, knowledge system and worldview. Later the interviews were compared with each other and analyzed. Therefore, interview data and field observations were subjected to interpretative discourse analysis on its own, and assisted the Q factor analysis by including respondents' interpretations of statements when analyzing the factors.

\section{RESULTS}

The factor analysis revealed that there are two operating discourses in the KBR, and that these discourses have a clear stakeholder division. All respondents in the P-set loaded on a factor. The three CapeNature representatives loaded on factor 1, and the four fishers on factor 2 . The natural and social scientists were split. The two natural scientists load on factor 1, while 
the two social scientists load on factor 2 . The discourse held by CapeNature and the natural scientists will in the following be referred to as the "scientific discourse," while the fishers and the social scientists adhere to the "livelihood discourse." The Eigen value of the scientific discourse is 5.3067, while it is 2.1598 for the livelihood discourse. The composite reliability is 97.3 and $96 \%$, respectively.

The two "ideal type" $Q$ sorts for the scientific and the livelihood discourse are shown below in Table 1. In the table they are presented from statements of "strongest consensus" to statements of "strongest deviation." Statements of high consensus refer to statements that have been sorted similarly on the "ideal type" Q sorts of both discourses. It shows what aspects do not distinguish significantly between the two discourses. Consensus does not automatically mean that the statement has scores in the middle (near 0), it can also be non-neutral. Table 1 shows that, according to the factor analysis, statements \#2, \#4, \#6, \#7, \#8, \#10, $\# 11$, \#17, \#21, and \#23 do not distinguish considerably between the different discourses but show common grounds between the two.

The statements of strongest deviation show what issues differ most between the two discourses. Table 1 shows that the most important statements of distinction are statements $\# 1$, $\# 3$, \#5, \#9, \#12, \#13, \#18, \#19, and \#20. These statements are statistically significant and therefore central when describing the discourses; they show the distinguishing issues and their relational importance. The interview data carried vital information explaining the respondents' thoughts on the issues highlighted in the statements, as well as the reasons why they sorted the way they did.

Furthermore, the results of the interpretative discourse analysis have been triangulated with the Q factor analysis to validate the factor interpretation. The following section will present the scientific discourse and the livelihood discourse in closer detail, interpreting both data from the Q factor analysis and the interpretative discourse analysis.

\section{The Scientific Discourse}

What is distinctive about this account is its normative management-based ecological approach. This discourse displays a strong concern about the destructive impact human behavior has on the environment. It emphasizes the necessity of creating management plans and projects to reach conservation objectives, and that these projects need to involve the fishers to succeed optimally.

Three statements are particularly important for this discourse, namely \#13, \#20, and \#5. These three statements happen to be the statements of strongest agreement for this discourse, while also being among the most distinguishing ones to the livelihood discourse. The statements of strongest disagreement are $\# 6$, \#8, and $\# 22$, however none of these statements are of great significance in defining this discourse in a comparative perspective to the other one, as all three are statements of consensus.

There is support for the idea that all citizens should take responsibility for environmental problems, and that the South African government has a statutory duty to protect marine biodiversity. According to this view, the Kogelberg belongs to the South African state and therefore all South Africans, not only the locals who live in the reserve. As commented by a natural scientist: "Just because they happen to live there next to that piece of coast, I don't see that that necessarily means ownership or users rights. Theoretically, all of the resources belong to the state. That's what it says in the constitution. (...) People living outside the KBR have concerns and a right to know that that is being managed properly for the benefit of all South Africans, not just the people who happen to live in it." Marine conservation in this context involves regulating people's utilization of the sea's resources. As pointed out by another natural scientist: "I do think that it's never fully recognized that, if you look at our law, all the sea and it's resources are held in trust for all South Africans. Not just the people who happen to live by the sea." These statements therefore concur with dominant discourses which stress that MPA's are particularly important in this regard in order to keep marine areas healthy, which is necessary for protecting marine species.

While a desire to strive toward "pristine" conservation ideals is present in the scientific discourse, regulation of human activities and more specifically the presence of people are cited as an important environmental and social challenge in achieving this state. In the interviews, this was demonstrated by the following response: "A MPA, which is less than $10 \%$ of an entire coastline, needs to be pristine. Not to do away with people's right to catch fish. But to have an area where we know what it used to be like. That is also an ideal place to monitor change. Climate change and change that doesn't come through human pressures. So it's got a very critical need." (CapeNature Official). This discourse expresses support for the viewpoint that local communities' use of marine resources is an important factor in species being threatened. In the interviews, both scientists and CapeNature representatives directly referred to the tragedy of the commons scenario when discussing the issue of fishers as protectors (statement \#13). Following this view, the primary objective of the fishers is to optimize their daily economic return. According to one CapeNature official, "obviously fishermen are concerned about their resource, but the problem is the tragedy of the commons scenario. If you don't catch the fish, the next person is going to catch the fish." Having to act according to one's own self-interest instead of "the common good" is closely connected to the socio-economic reality of fishers' dependency on marine species to provide means of securing the necessities of life. According to this approach, conservation is also a matter of education, as locals harvesting marine resources may not always have sufficient knowledge of the biological repercussions. Central here is the assumption that protecting marine species will result in gains for the fishers in the long term. While holding positions for conservation with limited human interference to protect stocks, there is also recognition of the idea that it is important to include local fishers and other environmental users in conservation efforts, and that this is regarded a prerequisite for management projects to succeed. To this a scientist explained: "We must include fishers, otherwise we are doomed to fail. The more desperate and poor the fishers are, the more difficult it is. It's quite easy in America or Australia where you've got an educated fishing population. It's not a walk in the park, but it's a hell of a lot 
easier than when you've got a desperately hungry fishing population that has had the disservice of an apartheid education."

\section{The Livelihood Discourse}

What is distinct of this view is a strong concern about the social implications brought about by the Kogelberg as a BR, particularly injustice toward the fishers and the fishing communities. The key concern is that although nature needs to be sustained, conservation of marine areas cannot deprive people of their livelihoods. Importantly, this discourse also expresses a strong opposition to the Kogelberg MPA. During an interview this was passionately expressed by a fisher who thought that "The MPA is absolutely worthless. As far as the fishermen are concerned, it was stolen from them."

The most influential statements of agreement in defining this discourse are \#18 and \#19, as well as \#3 and \#12. The most important statements of disagreement are $\# 1$ and \#9. In the interviews, the fishers describe their respective villages and the ocean as something that is part of them, and something that belongs to them. With family bounds dating back generations, they believe that living from fishing is their inherited right and part of their identity. Conserving nature is talked about as a way of life where one coexists with other species, in contrast to creating and enforcing policies. The current arrangement with the MPA and fishing rights processes is considered as unfair and unnecessary. These sentiments, which were continuously expressed during interviews with the fishers, were related to their opinions on commercial fishing boats that catch vast amounts of fish. A fisher from Kleinmond explains: "I think the big boats are taking all our fish out of the water. Then when we go to sea there is nothing left for us. It's a major problem for us because they come very near to the shore." Another aspect linked to this is a feeling of inequality. Being among the poorest in the KBR, the fishers feel restricted by fishing rights and the fact that they are prohibited from fishing in the MPA as they have previously done. A fisher explained his position by adding: "People should be taken into consideration. I think it can't just be imposed without the public impact. They just took an area and declared it a protected area. No one could say anything at all. It was the fisher's favorite fishing spots. And now they are sentenced out of it. It's illegal to fish there, and that are the best places to fish. Then you get a clash of interests. The fishermen feel they are not acknowledged when it becomes illegal. The responsibility is certainly taken away from us." What also became apparent was that some fishers hold resentments toward white people of the area whom they believe are not penalized for "breaking the rules," e.g., when they are planting alien trees in their gardens or dislocating sand from the beaches. This can be understood as an expression of injustice on behalf of the poor fishing population, as they believe conservation restrictions are imposed on them alone.

The livelihood discourse indicates that the fishers think and understand marine conservation differently than the other stakeholders. However, the social scientists have sorted their Q sorts similarly to the fishers and therefore loaded higher on factor 2, or the livelihood discourse. The interview data shows that although the fishers and the social scientists load on the same factor, there is an important difference between these two groups. While the fishers refer to their own personal experience and livelihood challenges, the social scientists who work in these communities emphasize that although they do not relate to the situation in the same way, they do understand and generally support the viewpoint of the fishers. To this a social scientists responded to statement \#2 (living with the sea is my way of existing) by adding: "That's not relevant to me but I can see that it's relevant to a lot of people who live in the Kogelberg. So I would strongly agree with somebody who said that, of course. My job is linked to it, but I wouldn't say it's my way of existing personally."

One of the biggest concerns for the fishers, and also recognized as important aspect by the social scientists, is that the current functioning of the KBR is depriving people of their livelihood. Here, a social scientist added: "The KBR is a particular concept. It's a foreign concept to most people out there. It was not very well brainstormed, not very well discussed, not very well implemented. So I can understand that most people don't really like what they see there because most of the projects run by the KBR have been very conservationist. There's very little livelihood development, or socio-economic benefits to the community living there." Therefore, the focus on social issues needs to be understood in the context of several social challenges, which include abalone poaching, violence, crime and drug abuse. Uncertain fishing rights and stricter conservation controls being exercised not only expose fishers and their livelihoods to vulnerabilities, but also exacerbate existing community challenges.

\section{Importance of Stakeholders' Lived Experience}

While the factor analysis demonstrates that there are two distinct discourses operating among the KBR stakeholders, certain viewpoints are shared between the two. "Consensus" is found among more "neutral" or less important statements, such as \#10, \#11, \#23, but also among non-neutral statements such as \#2 and $\# 21$. What is important to note is that although there is (dis)agreement between the discourses, this (dis-)agreement is found on two different parts of the discourses. Although both groups disagree strongly with a statement, this disagreement is based on a different way of thinking about the subject matter. For instance, both the scientific and the livelihood discourse respondents strongly disagreed with statement \#22 ("I need to be allowed to do what I need to do to make a living, although it means that some plant or animal species might go extinct."). Although there is consensus among the stakeholders that they disagree with this statement, the interview data show that three of the fishers had problems sorting this statement before it eventually ended up on strongly disagree. While one fisher said he would rather die hungry, the other fishers explained this as a difficult dilemma that is hard to answer.

"I would rather die poor than to exploit that for my benefit (point at the sea). I would feel bad when I die if I plundered to get a nice car. That's not what I'm about. Maybe that's why I'm so poor (laughs)."

Fisher, Kleinmond "When you got to eat, you got to eat. Either you go extinct or it goes
extinct. It's a difficult one."

Fisher, Pringle Bay 
The respondents falling under the scientific discourse recognized that there is a difference between not wanting to cause something to go extinct in theory and actually being in that situation. There was general agreement that letting a species go extinct is very selfish and morally wrong, however, because the respondents in this group have never been in that position they emphasized that it was hard to relate to it. Here a natural scientist added: "Me putting it in the 'I disagree with' is obviously indicative of my upbringing and social conditions in life and the fact that I haven't been put in the position where it's me or something else." This phenomenon was also found in other consensus quotes, such as statement \#2 ("Living with the sea is my way of existing."), a non-neutral statement both discourses agree with. The sea provides a livelihood for all the respondents, although somewhat indirectly for some interviewed stakeholders. Nevertheless, respondents generally expressed a strong relationship with the sea, predominantly on different grounds. While recreational and job-related activities were crucial to both systems of belief, the supporters from the scientific discourse talked about ecosystem services, while the fishers brought up their direct dependency on consuming and selling marine species to sustain their livelihoods.

What these examples indicate is the importance of how lived experience influences stakeholders' thoughts and ideas. People in the KBR experience and understand nature in different ways depending on how they live their lives. The concept of "biodiversity conservation" has different meanings to different stakeholders, and this meaning emerges in relation to practice. This research therefore supports the claim that our definition of "nature" is constructed by us giving it a certain meaning, as well as by discursive processes. Thus, what we understand as "natural" is also social and cultural (Escobar, 1999: p. 2).

\section{DISCUSSION}

\section{The MPA As a Source of Dispute}

All the stakeholders who participated in this study emphasized the importance of conserving both natural resources and livelihoods, as the two are closely linked. In this regard, the primary concern of the scientific discourse was the natural environment, while the social issues related to the BR were of greatest importance to the respondents falling under the livelihood discourse. In contrast to the CapeNature representatives and the natural scientists who considered it a necessary conservation means, fishers perceived the imposition of a protected area as taking away their responsibility to act as custodians of "their" marine resources. This finding is not surprising, as other studies that included documenting and analyzing perceptions of biodiversity conservation in South Africa have found similar attitudes recorded from community members living adjacent or near protected areas (Sunde and Isaacs, 2008; Watts and Faasen, 2009; Williams, 2013). Research undertaken by Faasen (2006) and Watts and Faasen (2009) in the Tsitsikamma, South Africa, for instance investigated whether synergies existed between biodiversity conservation and sustainable rural development, and documented local community members' perceptions of the no-take policy of the MPA in the area. This work highlighted that local communities harbor discontent and opposing views toward the conservation mandate of the management authorities and that there was a need to foster better involvement and participation of community members in decision-making processes. Similarly, Williams' (2013) study in the same area highlighted that the local communities historically had access to various fishing sites until the proclamation of the national park and subsequently the establishment of a "no-take" MPA. It was found that community members and fishers alike did not regard the current management and status quo as legitimate, and continuously referred to historical and traditional fishing practices as evidence of their rights to access the current MPA and its fisheries resources (Williams, 2013: p. 13). While opposing views of what exactly constitutes conservation and how this may result in discontent especially from neighboring communities toward MPAs, Sunde and Isaacs (2008: pp. xiii, 19-22) noted that a key area of concern relates to the fact that communities perceive themselves as bearing the costs of marine conservation with limited benefits in return. What exacerbates the conflict is that in some cases current practices of protected areas were not perceived as a legitimate conservation approach among communities, especially where locals were not involved in the conceptualization or implementation of these areas. These examples show that conflict and disputes between stakeholder groups are already found on the discursive level, as stakeholders possess dissimilar systems of belief. These trends are disturbing, as creating and sustaining MPAs is a key conservation strategy for the South African government, which has expressed its commitment to meet international and related national obligations toward protecting its biodiversity. One of these is to ensure that local communities participate in conservation efforts, which could come up against several challenges if these efforts threaten to undermine local livelihoods (Sunde and Isaacs, 2008: p. xiv).

\section{Championing Conservation Cooperation}

Conflicts and disputes over natural resources are present across the world and therefore not unique to the South African context. What is significant in the South African experience is that the conservation approach was influenced by historical and political trends of the time. This meant that the country's conservation approaches were largely influenced by discriminative events and practices, and resulted in differing discourses in relation to environmental protection. These differences saw a conservation paradigm that was based on being exclusionary, riddled with conflict, and alienating the majority of the country's people to the objectives of conservation areas (Carruthers, 1989: p. 215). However, with the advent of democracy in the early 1990 's, there was a need to address the deep inequalities and misconceptions that were woven into everyday discourses and the legal fabric of environmental legislation and management. Perceptions about the environment and the protectionist approaches demanded urgent attention in the government's postapartheid environmental planning (Wynberg, 2002: p. 234), and emphasis was placed on the need for meaningful engagement between stakeholders involved in conservation planning and management. South Africa has made significant progress in 
developing policies to address environmental priorities and social development. Yet the debilitating legacies of apartheid, coupled with contemporary politics, environmental concerns and pressures to ensure and promote sustainable use and access to natural resources, still present various challenges for achieving conservation goals. One such challenge is ensuring effective implementation and enforcement of policy and legislation, as well as monitoring policy outcomes ${ }^{14}$. This is related to the continued top-down decision-making processes in natural resource management, marginalization of local communities, and the dominant scientific narrative in conservation management, which have been well documented in earlier studies in the regional context (Sunde and Isaacs, 2008: p. 5; Müller, 2010: p. 153; Sowman, 2011: p. 299; Williams, 2013: p. 13; Sowman et al., 2014: p. 31).

Many biodiversity-rich areas are subject to conservation strategies of some form and should include people as part of its biodiversity. In a developing country context, these people are typically among the economically poor who depend on natural resources to contribute to their livelihoods. While various conservation paradigms, such as the dominant discourse of sustainable development, recognize inclusive and participatory approaches, their implementation often fails. However, the ways in which people relate to nature, biodiversity, or species extinction varies greatly. Being rooted in different discourses, the ways in which environmental concepts are perceived depend on people's relational lived experience. Locals might not agree to the fundamental principles of conservation and, while being recognized as stakeholders, it has been difficult to integrate their system of belief into existing conservation approaches. Here, the importance of understanding these environmental discourses becomes apparent and highlights the need for more contextspecific research of BRs and protected areas, including the social environment that is part of these systems.

A key issue that results in cooperation difficulties is related to discursive ideas of how biodiversity should be protected (Hyman, 2006: pp. 84-88). This was stressed by fishers who claimed that their interests and perceptions on marine biodiversity conservation, as well as their traditional way of life, were marginalized and not considered in conservation objectives. It is important to stress however that even if these conditions were met, this would not necessarily mean better cooperation between the stakeholders managing a protected area. What is key though is to acknowledge that communities and local stakeholders are part of the area that needs protection, and that their "buy-in" and inputs are necessary in order to collectively work toward meeting conservation objectives. Coupled to this ideal is that conservation practices should be viewed as socially just and should work toward "understanding how people perceive an issue [which] is essential to the whole process of 'problem identification,' both normatively and politically" (Barry and Proops, 1999:338).

The KBR is a case in which different discursive ideas of how biodiversity should be protected result in cooperation

\footnotetext{
${ }^{14}$ South African National Biodiversity Institute website: http://www.sanbi. org/biodiversity-science/science-policyaction/biodiversity-policy Accessed 22.06.2016.
}

difficulties among stakeholders and limited outcomes (Hyman, 2006: pp. 84-88). On these grounds, the authors would like to stress the importance and encourage more context-specific socioeconomic research regarding the establishment, implementation and maintenance of protected areas. Conservation efforts and projects will continue to fail if the belief systems, inputs and ways of life of local communities (and other relevant stakeholders) are not taken into account. In this regard, conservation should be a part of people's discourses, part of their livelihoods and not seen as a burden, exercise or an approach that instills fear or compromising on one's livelihood. While including people and incorporating their knowledge and way of life does not automatically mean that conservation will succeed, it is an important priority that cannot be overlooked and should be included when initiating and implementing conservation objectives.

\section{Evaluation of Q Methodology}

This study has demonstrated that Q methodology can provide a valuable tool for researching environmental subjectivities. Drawing on the strengths of both qualitative and quantitative research traditions, it offers a promising method for studying perception-based research and makes an important contribution to science as it is able to identify and analyze multiple discourses. The application of Q methodology in all its stages is an efficient, yet demanding task. Nevertheless, it provides a reliable and logical framework for studying perceptions with validated results. The statistical nature of the Q factor analysis provides outcomes and data interpretations that are less prone to researcher bias. By combining interpretative discourse analysis with $\mathrm{Q}$ in this study, it revealed that this combination worked well in verifying results and providing deeper meaning and insights to the data. The study undertaken here thus concurs with the findings of Wolsink (2004), who emphasized that Q is particularly suitable for research that combines it with other research methods (Wolsink, 2004: p. 2676), such as participant observation.

\section{Limitations}

One methodological limitation is related to the sample size; in this regard, a small P-sample size carries some limitations. Here, it implies a finite number of factors to reach the Eigenvalue level of 1.0. This is because the Eigenvalue $\leq 1.0$ indicates that the unrotated factor explains less than the variance of one respondent, so with a small number of respondents this might happen sooner. Thus, it may be that a larger sample size, and particularly when recruited from other stakeholder groups, would have resulted in more discourses. Another methodological shortcoming is the double meaning as well as reasoning of some statements, which required careful qualitative analysis of the interview data and thereby put extra emphasis on the interpretative discourse analysis.

This study has studied a very heterogeneous group of people with major socio-economic diversities. This represented a challenge particularly when selecting statements, as the stakeholder groups tended to use language quite differently. One can therefore not reject the possibility that sensitivity to formulations has had an impact on the $\mathrm{Q}$ sorting procedure. 
Particularly consensus statements following the Q factor analysis might be a result of the statements being poorly formulated. The possibility therefore exists that some of the consensus statements could have been sorted differently if it was formulated in another way. It should also be noted that although there were clear stakeholder groupings in this study, other members of these groups might not share the same ideas, as these groups were not homogenous. The fishers as example might perceive marine conservation differently than the overall local community. Although all the fishers in this study shared similar ideas, a Q study that only focused on the fishers might have shown a wider spectrum of perceptions within the fishing community.

Perceptions of marine biodiversity conservation are part of a larger environmental discourse, which is further related to people's wider ontological worldview and systems of knowledge. Additionally, it is not static and will change and develop over time. Therefore, this research can only provide a limited description of the prevailing discourses, at best highlighting the most prominent similarities and differences. The authors therefore note that the research is not directly transferable or intended to prescribe conservation management. The aim is rather to demonstrate that the use of Q methodology is relevant and can provide reliable analysis for scrutinizing perceptionbased research. Q methodology allows researchers to understand the perceptions and interests of people in their own terms and categories rather than making assumptions. Therefore, based on this study's outcomes, the authors would strongly encourage further application of Q methodology in other studies in order to increase the amount of research that aims to conceptualize and analyze context-specific environmental challenges.

\section{CONCLUSION}

Conserving biodiversity is an important endeavor and one of the greatest contemporary environmental challenges. The KBR is an exceptionally biodiversity-rich area, which should be conserved. In doing this, the need for stakeholder engagement and cooperation has been identified and established in the form of the KBRC and various working groups (Anchor Environmental, 2009: p. 4). Previous studies have shown that stakeholders in the KBR are facing management and cooperation difficulties by pointing at divergent interests and perceptions (Hyman, 2006: pp. 84-88; Müller, 2010: p. 152). This study has contributed to research on how different perceptions and understandings of conservation influence the conservation objectives and activities of a BR. In doing so, this study set out to investigate how marine biodiversity conservation is perceived in the KBR by examining different discursive realms, and how stakeholders adhere to these discourses. It targeted stakeholders of the

\section{REFERENCES}

Addams, H., and Proops, J. (2000). Social Discourse and Environmental Policy: An Application of Q Methodology. Cheltenham: Edward Elgar.

Anchor Environmental (2009). Kogelberg Coast Integrated Management Plan: Report of the Organized Conservation Focus Group Meeting 13 October
KMWG, who is tasked with promoting and ensuring coastal conservation and development. This study has found varying ideas of what constitutes biodiversity conservation and how it should be implemented. It further highlighted some of the difficulties and challenges for cooperation in this particular case. The case study has presented two different ways of perceiving marine biodiversity conservation among stakeholders of the $\mathrm{KBR}$, which is grounded in different discourses. While these two differing discourses have highlighted specific positions, there was a common concern shared for the current environmental situation in the reserve. This was revealed in the importance and shared belief that protecting nature is of significant importance and to everyone's benefit. Another important finding was that there was a shared belief by stakeholders who all agreed that local communities and their livelihoods should be a key consideration in all conservation approaches.

While researching perceptions is not an easy task, this study employed Q methodology to demonstrate how perception based research can be validated. This study provided insights into the discourses present at a particular time in the area. Taken the complexity of the issue and the shortcomings of doing this exploratory study, in many ways, this research begs a companion piece to describe the different discourses in closer detail. In conclusion, the authors would like to emphasize the importance of increasing the number of research projects that study environmental discourses, as it is crucial to understand the social context and implications for conservation initiatives. While there is a need to conserve biodiversity globally, it is important to bring people into the debate and how they think, talk about and see themselves in or as part of the natural environment. Understanding the ways in which people think about conservation in particular is key when considering that it is not only a scientific problem but also a societal problem.

\section{AUTHOR CONTRIBUTIONS}

$\mathrm{KH}$ conducted research as part of her masters course under the supervision of SW. For this publication $\mathrm{KH}$ and $\mathrm{SW}$ worked in co-operation to produce the manuscript submitted here.

\section{ACKNOWLEDGMENTS}

The authors would like to thank Prof. Maarten Wolsink for methodological and analytical guidance. We are also grateful to Dr. Yves Van Leynseele and Dr. Maarten Bavinck for comments, and Dr. Judy McKenzie for help with the analysis. We also want to thank Stephen Young for creative inputs, as well as three anonymous reviewers for their comments during the manuscript review phase.

2009. Available online at: http://www.anchorenvironmental.co.za/Documents/ Pdfs/Kogelberg\%20CIMP/Minutes\%20-\%20Conservation\%20AgenciesFocus \%20meeting\%20KCIMP.pdf (Accessed June 21, 2016).

Baker, R. M. (2006). Economic rationality and health and lifestyle choices for people with diabetes. Soc. Sci. Med. 63, 2341-2353. doi: 10.1016/j.socscimed.2006.06.007 
Barry, J., and Proops, J. (1999). Seeking sustainability discourses with Q methodology. Ecol. Econ. 28, 337-345. doi: 10.1016/S0921-8009(98)00053-6

Bischof, B. G. (2010). Negotiating uncertainty: framing attitudes, prioritizing issues, and finding consensus in the coral reef environment management "crisis". Ocean Coast. Manag. 53, 597-614. doi: 10.1016/j.ocecoaman.2010. 06.020

Brown, S. R. (1993). A primer on Q methodology. Operant Subject. 16, 91-138.

Carruthers, E. (1989). Creating a national park, 1910 to 1926. J. South. Afr. Stud. 15, 188-216. doi: 10.1080/03057078908708197

Dasgupta, P., and Vira, B. (2005). "Q methodology' for mapping stakeholder perceptions in participatory forest management," in Institute of Economic Growth Working Paper Series No. E/264/2005 (New Delhi: Institute of Economic Growth).

Dryzek, J. S. (2013). The Politics of the Earth, 3rd Edn. Oxford: Oxford University Press.

du Plessis, T. C. (2005). A Theoretical Framework of Corporate Online Communication: A Marketing Public Relations (MPR) Perspective. Pretoria: University of South Africa.

Eden, S., Donaldson, A., and Walker, G. (2005). Structuring subjectivities? Using Q methodology in human geography. Area 37, 413-422. doi: 10.1111/j.14754762.2005.00641.x

Escobar, A. (1999). After nature: steps to an antiessentialist political ecology. Curr. Anthropol. 40, 1-30. doi: 10.1086/515799

Faasen, H. (2006). "Synergies between Biodiversity Conservation and Sustainable Rural Development of Adjacent Communities: A Case Study of the Tsitsikamma National Park," Unpublished master's thesis, Stellenbosch University, Stellenbosch.

Gallagher, K., and Porock, D. (2010). The use of interviews in Q methodology card content analysis. Nurs. Res. 59, 295-300. doi: 10.1097/NNR.0b013e3181e 4 ffff

Guimaraães, M. H. (2010). The use of Q-methodology to obtain stakeholder discourses on the future development of Ria Formosa coastal zone, South of Portugal. Rev. Portuguesa Estudos Regionais 23, 5-19.

Hagan, K. (2016). "Oceans of Discourses: a Q Study on Perceptions of Marine Biodiversity Conservation in the Kogelberg Biosphere Reserve, South Africa," Master Thesis, forthcoming, September 2016, University of Amsterdam, Amsterdam.

Hajer, M., and Versteeg, W. (2005). A decade of discourse analysis of environmental politics: achievements, challenges, perspectives. J. Environ. Policy Plan. 7, 175-184. doi: 10.1080/15239080500339646

Heracleous, L. (2006). Discourse, Interpretation, Organization. Cambridge: Cambridge University Press. Available online at: http://www.heracleous.org/ uploads/1/1/2/9/11299865/0521844029c1.pdf (Accessed May 4, 2016). doi: $10.1017 / \mathrm{CBO} 9780511488573$

Hyman, G. M. (2006). "How a Powerful Minority Has Exploited UNESCO Biosphere Reserve Status: A Case Study of the Kogelberg Biosphere Reserve, South Africa," Master Thesis, Sciences Po, Paris.

Johns, A., and Johns, M. (2001). Kogelberg Biosphere Reserve: Heart of the Cape Flora. Cape Town: Struik.

Kalof, L. (2000). "The multi-layered discourses of environmental concern," in Social Discourse and Environmental Policy: An Applications of Q Methodology, eds H. Addams and J. Proops (Northhampton, MA: Edward Elgar Publishing), 174-195.

Kearns, C. (2010). Conservation of biodiversity. Nat. Educ. Knowl. $3,17$.

Müller, K. (2010). Creating public value through collaborative environmental governance. Administratio Publica 18, 141-154.

Næss, A. (1974). Økologi, Samfunn og Livsstil: Utkast til enØkosofi. Oslo: Universitetsforlaget.

Niemeyer, S., Petts, J., and Hobson, K. (2005). Rapid climate change and society: assessing responses and thresholds. Risk Analysis 25, 1443-1456. doi: 10.1111/j.1539-6924.2005.00691.x

Pike, K., Wright, P., Wink, B., and Fletcher, S. (2014). The assessment of cultural ecosystem services in the marine environment using Q methodology. J. Coast. Conserv. 19, 667-675. doi: 10.1007/s11852-014-0350-z
Sowman, M. (2011). New perspectives in small-scale fisheries management. Challenges and prospects for implementation in South Africa. Afr. J. Mar. Sci. 33, 297-311. doi: 10.2989/1814232X.2011.602875

Sowman, M., Sunde, J., Raemaekers, S., and Schultz, O. (2014). Fishing for equality: Policy for poverty alleviation for South Africa's small-scale fisheries. Mar. Policy 46, 31-42. doi: 10.1016/j.marpol.2013.12.005

Stephenson, W. (1953). The Study of Behaviour: Q Technique and its Methodology. Chicago, IL: University of Chicago Press.

Stoll-Kleemann, S., and Bertzky, M. (2004). Linking Governance and Management Perspectives with Conservation Success in Biosphere Reserves -The GoBi-Project. Available online at: http://www.mnf.uni-greifswald.de/ fileadmin/Geowissenschaften/geographie/angew_geo/Publikationen/StollKleemann-Publikationen/Stoll-Kleemann_Bertzky_Artikel_BRIM_2004_ final_korr.pdf (Accessed June 10, 2015).

Sunde, J. (2014). Marine Protected Areas and Small-scale Fisheries in South Africa: Promoting Governance, Participation, Equity and Benefit Sharing. Chennai: ICSF.

Sunde, J., and Isaacs, M. (2008). Marine Conservation and Coastal Communities: Who Carries the Costs? A Study of Marine Protected Areas and their Impact on Traditional Small-scale Fishing Communities in South Africa. Chennai: ICSF.

United Nations (2002). Report of the World Summit on Sustainable Development. New York, NY: United Nations.

Tucker, C. (2013). Developing Sustainability Indicators for the Kogelberg and Cape West Coast Biosphere Reserves, South Africa, Master thesis, Stellenbosch University, Stellenbosch.

Turpie, J., Clark, B., Hutchings, K., Orr., K., and de Wet, J. (2009). Ecology, Value and Management of the Kogelberg Coast. Report prepared for WWF-CAPE Marine Programme, Cape Town: Anchor Environmental Consultants.

Van Exel, J., and de Graaf, G. (2005). Q Methodology: A Sneak Preview. Available online at: https://www.researchgate.net/profile/Gjalt_Graaf/ publication/228574836_Q_Methodology_A_Sneak_Preview/links/ 02bfe50f946fc9978b000000.pdf

Watts, S., and Faasen, H. (2009). Community-based conflict resolution strategies for sustainable management of the Tsitsikamma National Park, South Africa. South African Geograph. J. 91, 25-37. doi: 10.1080/03736245.2009.9725327

Watts, S., and Stenner, P. (2012). Doing Q Methodological Research: Theory, Method and Interpretation. London: Sage Publications Ltd. doi: 10.4135/9781446251911

Webler, T., Danielson, S., and Tuler, S. (2009). Using Q Method to Reveal Social Perspectives in Environmental Research. Greenfield, MA: Social and Environmental Research Institute.

West, S., Cairns, R., and Schultz, L. (2016). What constitutes a successful biodiversity corridor? A Q-study in the Cape Floristic Region, South Africa. Biol. Conserv. 198, 183-192. doi: 10.1016/j.biocon.2016.04.019

Williams, S. (2013). Beyond Rights: Developing a Conceptual Framework for Understanding Access to Coastal Resources at Ebenhaeser and Covie, Western Cape, South Africa, Doctoral Thesis, University of Cape Town, Cape Town.

Wolsink, M. (2004). Policy beliefs in spatial decisions: contrasting core beliefs concerning space-making for waste infrastructure. Urban Studies 41:13. doi: $10.1080 / 0042098042000294619$

Wynberg, R. (2002). A decade of biodiversity conservation and use in South Africa. S. Afr. J. Sci. 98, 233-243.

Conflict of Interest Statement: The authors declare that the research was conducted in the absence of any commercial or financial relationships that could be construed as a potential conflict of interest.

Copyright (c) 2016 Hagan and Williams. This is an open-access article distributed under the terms of the Creative Commons Attribution License (CC BY). The use, distribution or reproduction in other forums is permitted, provided the original author(s) or licensor are credited and that the original publication in this journal is cited, in accordance with accepted academic practice. No use, distribution or reproduction is permitted which does not comply with these terms. 